\title{
FACTORS INFLUENCING THE SEVERITY OF PAIN IN PATIENTS WITH PERIPHERAL DIABETIC NEUROPATHY
}

\section{SINAN MA AL-MAHMOOD ${ }^{1 *}$, TARIQ ABDUL RAZAK ${ }^{2}$, NIK NUR FATNOON NIK AHMAD ${ }^{3}$, ABDUL HADI MOHAMED ${ }^{4}$, SHAHRIN TARMIZI CHE ABDULLAH ${ }^{3}$}

\begin{abstract}
${ }^{1}$ Department of Basic Medical Sciences, Kulliyyah of Nursing, International Islamic University Malaysia, Level 2, Jalan Hospital Campus, 25710 Kuantan, Pahang Darul Makmur, Malaysia. ${ }^{2}$ Department of Basic Medical Sciences, Kulliyyah of Medicine, International Islamic University Malaysia, Bandar Indera Mahkota Campus, Jalan Sultan Ahmad Shah, 25200 Kuantan, Pahang Darul Makmur, Malaysia. ${ }^{3}$ Department of Internal Medicine, Kulliyyah of Medicine, International Islamic University Malaysia, Bandar Indera Mahkota Campus, Jalan Sultan Ahmad Shah, 25200 Kuantan, Pahang Darul Makmur, Malaysia. ${ }^{4}$ Department of Anaesthesiology and Intensive Care, Kulliyyah of Medicine, International Islamic University Malaysia, Bandar Indera Mahkota Campus, Jalan Sultan Ahmad Shah, 25200 Kuantan, Pahang Darul Makmur, Malaysia. Email: sinan.almawla@gmail.com
\end{abstract}

Received: 17 May 2017, Revised and Accepted: 04 July 2017

ABSTRACT

Objective: The principal aim of this study was to identify factors influencing the severity of peripheral diabetic neuropathy pain (PDNP), a symptom of the common neurological complication of diabetes mellitus, and peripheral diabetic neuropathy.

Methods: A cross-sectional study was performed using two self-administered questionnaires among subjects recruited from outpatient clinics at Hospital Tengku Ampuan Afzan, Kuantan, Malaysia. The Neuropathic Pain-4 tool was used to evaluate the presence of PDNP, and the Short-Form McGill Pain Questionnaire (MPQ) was used to characterize and determine the severity of PDNP. Sociodemographic and clinical data were collected from the patients.

Results: The MPQ indicated that most patients reported experiencing mild pain for all sensory pain descriptors other than throbbing and aching (mostly reported to be moderate) and hot-burning (mostly reported to be no pain). The severity of pain was found to be significantly related to the length of time for which the patients had suffered from diabetes in those patients who had been diagnosed over 10 years previously ( $\mathrm{p}=0.04$ ). Indian patients reported a higher severity of pain overall $(\mathrm{p}=0.04)$. No significant relationship was found between pain severity and any of the following factors: Type of diabetes (I or II), gender, smoking status, alcohol consumption, obesity, medication taken, or presence of other diseases.

Conclusion: In this study, most patients with PDNP reported the severity of the pain to be "mild." The pain severity may be influenced by a patient's ethnicity and the length of time for which they have suffered from diabetes.

Keywords: Factors, Severity of pain, Peripheral diabetic neuropathy.

(c) 2017 The Authors. Published by Innovare Academic Sciences Pvt Ltd. This is an open access article under the CC BY license (http://creativecommons. org/licenses/by/4. 0/) DOI: http://dx.doi.org/10.22159/ajpcr.2017.v10i10.20043

\section{INTRODUCTION}

Peripheral diabetic neuropathy pain (PDNP) is a complication of diabetes mellitus affecting many patients with that condition [1]. A neurological disorder, PDNP is defined as pain directly resulting from peripheral somatosensory system abnormalities in diabetic people; it is among the principal causes of increased mortality and morbidity [2]. As described in Tesfaye and Selvarajah [3], the foremost clinical indicators of PDNP are insensitivity (a consequence of which is an increased risk of injury and ulceration of the foot) and painful neuropathic symptoms. In comparison to painless diabetic neuropathy, painful diabetic neuropathy has a deleterious effect on patients' mental and physical quality of life [4]. The presence of chronic painful peripheral neuropathy over an extended period can be a cause of great distress to patients and may even lead to anxiety or depression. On the other hand, this type of complication lower the scale of quality of life of patients as the ratio of morbidity and mortality increased, whereas society undergo in extreme burden due to health-care cost [5].

One-fifth of patients with diabetes and one-third of patients with diabetic peripheral neuropathy experience painful symptoms [6]. The severity of the pain varies greatly, manifesting as, for example, aching, paresthesia (a tingling or pricking ["pins and needles"]), burning, a shooting pain, similar to an electric shock, or a lancing (or "stabbing") pain. However, the exact symptoms cannot be considered to be reliable indicators of nerve damage. Patients with little sensory deficit - and so little nerve damage - can experience the symptoms of severe pain; those with no pain can have exhibit evidence of nerve damage in the form of complete numbness of the foot, which is associated with a greatly elevated risk of ulceration [7]. In Malaysia, there is sparse information regarding PDNP incidence and severity.

PDNP pathogenesis remains a matter of some uncertainty although a number of theories have been proposed. One such theory involves autoimmune and metabolic disorders in combinations with glial cell activation and changes in the expression of calcium and sodium channels; another involves alterations to the blood vessels that supply the peripheral nerves [8]. Research has demonstrated a small number of drugs to be of benefit in pain reduction for PDNP. The use of combination therapy as a means of optimizing clinical outcomes has been investigated [9], but there has been insufficient research into the epidemiology of PDNP despite the high associated comorbidity [10].

\section{METHODS}

\section{Study design and participants}

This cross-sectional study to both evaluate and measure the intensity of pain of patients suffering from PDNP was performed using two selfadministered questionnaires, the Short-Form McGill Pain Questionnaire (MPQ) and the Neuropathic Pain-4 (DN4) tool.

The inclusion criteria for the subject were as follows:

- Age greater than 18 years

- Diagnosis of diabetic neuropathy for at least 12 months 
- No mental disability (for example, dementia, mental disorder, or Alzheimer's disease)

- Neuropathic pain attributed to diabetic neuropathy by the presence of four or more of the following symptoms contained on the DN4 assessment form:

- Painful: Electric shock, painfully cold, burning

- Non-painful: Tingling, itching, numbness, "pins and needles."

- No neuropathy pain due to other diseases

- Able to read and write in either English or Malay.

The subjects were recruited patients attending the clinics of the Medical Outpatient Department of a single Malaysian Hospital - the Hospital Tengku Ampuan Afzan (HTAA) in Kuantan, Pahang. Patients were given the questionnaire, written in both English and Malay, and the study information sheet. Those patients who agreed to participate in the study consented to their participation by signing an informed consent form (ICF) and any questions the patients had were answered. Patients were instructed by the researcher to complete the questionnaire by themselves and were given as much time as they required to do so. Subjects were then interviewed before their appointment in the clinic. Further to the collection of the MPQ and DN4, the information collated was fundamental sociodemographic details, details of their diabetes (type and duration), medications, alcohol consumption, smoking status, and other diseases.

\section{Ethical considerations}

The objective of the study was clearly explained to all participants. The ICF was attached to the questionnaire and signed by the subject before participation in the study. Subjects were assured that all information provided on the questionnaires would remain confidential. The collected data were used for academic purposes and exclusively for this study.

Ethical approval for the study was obtained from the HTAA Director, the Head of Department of the MOPD in the HTAA, the International Islamic University of Malaysia Research Ethics Committee (IREC-471) and the Ministry of Health Malaysia (NMRR-15-1998-28435).

\section{Measurement tools}

DN4 (Douleur Neuropathique-4, or 'Neuropathic Pain-4')

The DN4 tool is a screening tool used to determine the presence of neuropathic pain through the identification of the presence or otherwise of a number of forms of pain or associated sensations. It comprises 10 items; a positive item (indicating presence) is assigned a score of 1 , while a negative item (indicating absence) is assigned 0 . A diagnosis of neuropathic pain is indicated by a total of at least 4 when the scores are summed across all 10 items [11].

About 7 of the 10 items relate to the description of the pain and the associated, abnormal, sensations. The pain descriptors are painful cold, burning and electric shocks. The sensations are numbness, itching, tingling, and "pins and needles." The remaining three items, tactile dynamic allodynia (using a soft brush), pinprick hypoesthesia (using a toothpick), and touch hypoesthesia (using a soft brush) are evaluated in the painful area [11].

\section{Short-form $M P Q$}

Characterizing pain qualities, as shown in Fig. 1, on a four-point scale, the MPQ has become one of the most widely-used research and clinical tools in assessing pain since its introduction in 1987 [12]. 11 of the characteristics are seen as sensory pain descriptors - these are 1-11 in Fig. 1; the remaining four are viewed as affective terms associated with experiencing pain [13]. The ordinal scale used to score the 15 terms comprises four levels [14]: 0 (no pain), 1 (mild pain), 2 (moderate pain), and 3 (severe pain)

\section{Sample size}

The required sample size was calculated according to the following formula:

\begin{tabular}{|c|c|c|c|c|c|}
\hline S. No. & Type of Pain & $\begin{array}{l}\text { None } \\
(0)\end{array}$ & $\begin{array}{l}\text { Mild } \\
\text { (1) }\end{array}$ & $\begin{array}{l}\text { Moderate } \\
(2)\end{array}$ & $\begin{array}{l}\text { Severe } \\
(3)\end{array}$ \\
\hline 1 & Throbbing & 0 & 0 & 0 & 0 \\
\hline 2 & Shooting & 0 & 0 & 0 & 0 \\
\hline 3 & Stabbing & 0 & 0 & 0 & 0 \\
\hline 4 & Sharp & 0 & 0 & 0 & 0 \\
\hline 5 & Cramping & 0 & 0 & 0 & 0 \\
\hline 6 & Gnawing & 0 & 0 & 0 & 0 \\
\hline 7 & Hot-burning & O & 0 & 0 & 0 \\
\hline 8 & Aching & 0 & 0 & 0 & 0 \\
\hline 9 & Heavy & 0 & 0 & 0 & 0 \\
\hline 10 & Tender & 0 & 0 & 0 & 0 \\
\hline 11 & Splitting & 0 & 0 & 0 & 0 \\
\hline 12 & Tiring-exhausting & 0 & 0 & 0 & 0 \\
\hline 13 & Sickening & 0 & 0 & 0 & 0 \\
\hline 14 & Fearful & 0 & 0 & 0 & 0 \\
\hline 15 & Punishing-cruel & 0 & 0 & 0 & 0 \\
\hline
\end{tabular}

Fig. 1: The McGill pain questionnaire used in this study

Table 1: Subjects' sociodemographic and clinical characteristics

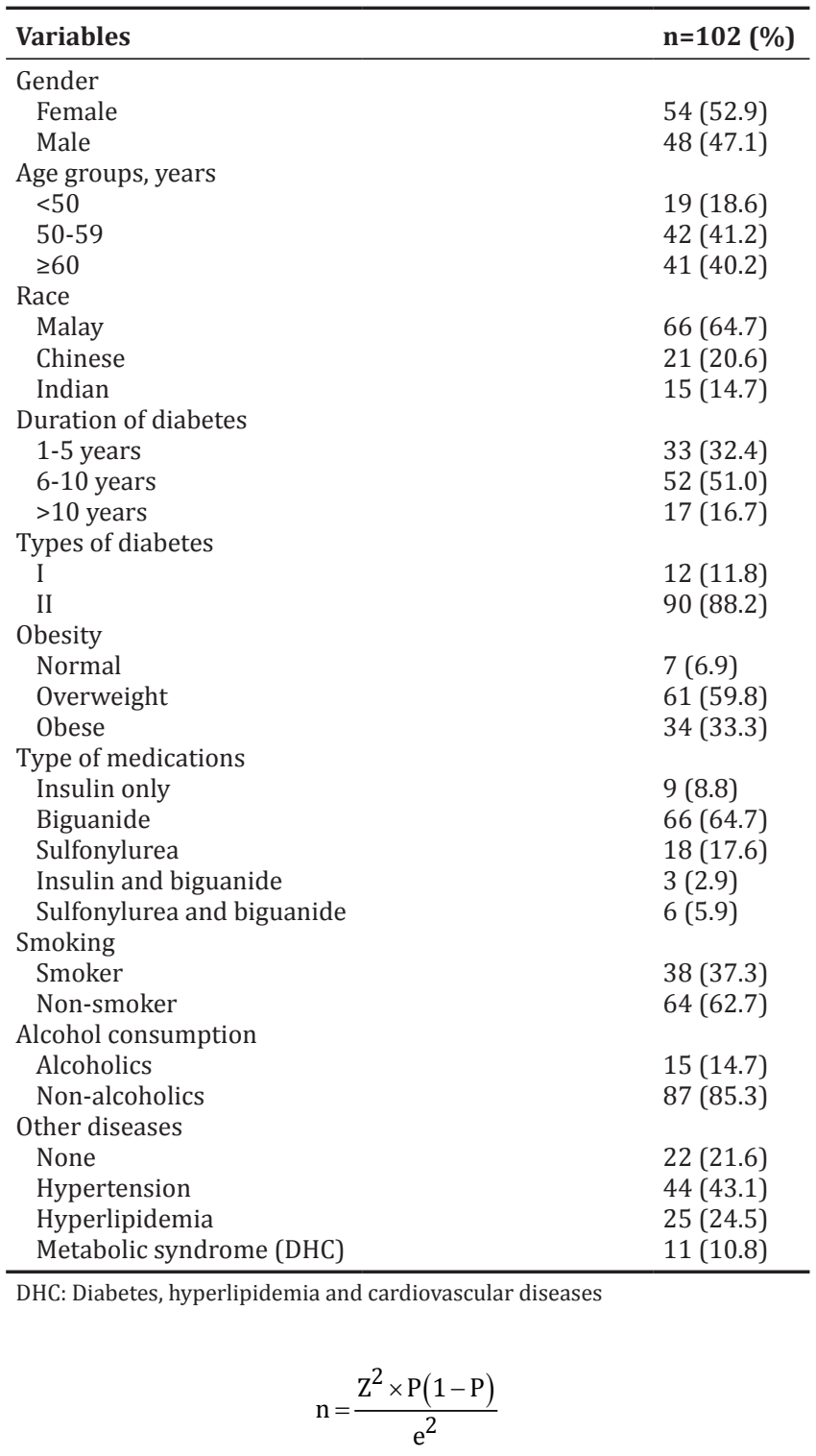

Where the value of $\mathrm{Z}$ was taken from the standard normal distribution corresponding to the desired confidence level (1.96 for a $95 \%$ confidence interval $[\mathrm{CI}]), \mathrm{P}$ is the expected exact proportion an e is the desired precision (one-half the desired $\mathrm{CI}$ width). To account for 
Table 2: Responses to the McGill questionnaire

\begin{tabular}{|c|c|c|c|c|c|}
\hline S.No. & Type of pain & None n (\%) & Mild n (\%) & Moderate n (\%) & Severe n (\%) \\
\hline 1 & Throbbing & - & $18(17.6)$ & $75(73.5)$ & $9(8.8)$ \\
\hline 2 & Shooting & $6(5.9)$ & $58(56.9)$ & $36(35.3)$ & $2(2)$ \\
\hline 3 & Stabbing & $8(7.8)$ & $70(68.6)$ & $21(20.6)$ & $3(2.9)$ \\
\hline 4 & Sharp & $15(14.7)$ & $65(63.7)$ & $20(19.6)$ & $2(2)$ \\
\hline 5 & Cramping & $34(33.3)$ & $60(58.8)$ & $7(6.9)$ & $1(1)$ \\
\hline 6 & Gnawing & $35(34.3)$ & $60(58.8)$ & $6(5.9)$ & $1(1)$ \\
\hline 7 & Hot-burning & $80(78.4)$ & $22(21.6)$ & - & - \\
\hline 9 & Heavy & $3(2.9)$ & $60(58.8)$ & $36(35.3)$ & $3(2.9)$ \\
\hline 10 & Tender & $9(8.8)$ & $72(70.6)$ & $18(17.6)$ & $3(2.9)$ \\
\hline 11 & Splitting & $40(39.2)$ & $51(50.0)$ & $11(10.8)$ & - \\
\hline 12 & Tiring - exhausting & - & $13(12.7)$ & $81(79.4)$ & $8(7.8)$ \\
\hline 13 & Sickening & $1(1.0)$ & $13(12.7)$ & $72(70.6)$ & $16(15.7)$ \\
\hline 14 & Fearful & - & $25(24.5)$ & $47(46.1)$ & $30(29.4)$ \\
\hline 15 & Punishing - cruel & $4(3.9)$ & $53(52.0)$ & $38(37.3)$ & $7(6.9)$ \\
\hline
\end{tabular}

the possibility of incomplete questionnaires being returned, 10\% was added to the total sample size. This yielded a sample size for the study of $n=(92+10)=102[15]$.

\section{Statistical analysis}

Results for continuous variables were expressed as the mean and standard deviations, while those for the categorical variables were expressed as percentages and frequencies. The differences in the overall Short-Form McGill Pain Score with regard to clinical characteristics and demographic variables were analyzed using one-way analysis of variance and independent samples t-tests. All data analysis was performed using SPSS, version 20.0 (SPSS Inc., Chicago, IL, USA). Results were considered significant at a $\mathrm{p}<0.05$.

\section{RESULTS}

\section{Subjects' demographic characteristics}

Table 1 summarizes the sociodemographic and clinical characteristics of the 102 subjects. Of these diabetic patients experiencing PDNP, two-thirds were Malay, approximately half were female and 95\% were overweight or obese. Approximately, oneseventh of the patients were alcoholics and over one-third (37\%) were smokers. $88 \%$ of patients had been diagnosed with Type II diabetes, while $51 \%$ received their diagnosis between 6 and 10 years before completing the questionnaire $(17 \%$ were diagnosed earlier than this). Only $9 \%$ of the subjects were treating their diabetes with insulin alone with a further $9 \%$ receiving combination therapy. $18 \%$ were treated with sulfonylurea, while $65 \%$ were treated with biguanide. In terms of other diseases, $25 \%$ subjects were suffering from hyperlipidemia, 11\% from metabolic disease and $43 \%$ from hypertension.

\section{DN4 tool and MPQ}

The results of the neurological assessment performed through the DN4 questionnaire provided a score for all respondents of at least 4 out of 10 , indicating the presence of diabetic neuropathy pain.

Table 2 shows the number of patients experiencing each intensity of pain for each of the terms on the MPQ. As can be seen in the table, the majority of patients reported "mild" intensity for all of the sensory descriptors, with three exceptions. The majority of patients reported no hot-burning pain, while "throbbing" pain and "aching" pain were both described as "moderate" by most patients. Severe pain was, in general, reported relatively infrequently, although over $40 \%$ of patients reported experiencing severe aching pain. Most of the affective descriptors caused moderate pain to most patients, the exception being "punishing-cruel," which 53 patients (52\%) described as "mild" pain.

Table 3 shows the influence of the sociodemographic and clinical factors on pain severity. The duration of diabetes was found to be associated
Table 3: Influence of sociodemographic and clinical characteristics on pain severity

\begin{tabular}{|c|c|c|}
\hline Variables & Mean \pm SD & p value \\
\hline \multicolumn{3}{|l|}{ Gender } \\
\hline Female & $19.91 \pm 4.33$ & \multirow[t]{2}{*}{0.266} \\
\hline Male & $20.79 \pm 3.64$ & \\
\hline \multicolumn{3}{|l|}{ Age groups, years } \\
\hline$<50$ & $19.79 \pm 4.63$ & \multirow[t]{3}{*}{0.712} \\
\hline $50-59$ & $20.21 \pm 3.83$ & \\
\hline$\geq 60$ & $20.68 \pm 3.99$ & \\
\hline \multicolumn{3}{|l|}{ Race } \\
\hline Malay & $19.97 \pm 4.14$ & \multirow[t]{3}{*}{0.040} \\
\hline Chinese & $19.71 \pm 3.48$ & \\
\hline Indian & $22.73 \pm 3.59 *$ & \\
\hline \multicolumn{3}{|l|}{ Duration of diabetes } \\
\hline 1-5 years & $19.15 \pm 4.14$ & \multirow[t]{3}{*}{0.038} \\
\hline $6-10$ years & $20.46 \pm 3.86$ & \\
\hline$>10$ years & $22.18 \pm 3.72^{*}$ & \\
\hline \multicolumn{3}{|l|}{ Types of diabetes } \\
\hline I & $21.33 \pm 3.44$ & \multirow[t]{2}{*}{0.308} \\
\hline II & $20.19 \pm 4.10$ & \\
\hline \multicolumn{3}{|l|}{ Obesity } \\
\hline Normal & $20.43 \pm 3.82$ & \multirow[t]{3}{*}{0.596} \\
\hline Overweight & $20.00 \pm 4.07$ & \\
\hline Obese & $20.88 \pm 4.04$ & \\
\hline \multicolumn{3}{|l|}{ Type of medications } \\
\hline Insulin only & $20.67 \pm 3.20$ & \multirow[t]{5}{*}{0.305} \\
\hline Biguanide & $19.71 \pm 4.07$ & \\
\hline Sulfonylurea & $21.56 \pm 3.66$ & \\
\hline Insulin and biguanide & $22.33 \pm 5.68$ & \\
\hline Sulfonylurea and biguanide & $21.83 \pm 4.62$ & \\
\hline \multicolumn{3}{|l|}{ Smoking } \\
\hline Smoker & $20.97 \pm 3.68$ & \multirow[t]{2}{*}{0.196} \\
\hline Non-smoker & $19.94 \pm 4.20$ & \\
\hline \multicolumn{3}{|l|}{ Alcohol consumption } \\
\hline Alcoholics & $19.67 \pm 3.59$ & \multirow{2}{*}{0.462} \\
\hline Non-alcoholics & $20.44 \pm 4.10$ & \\
\hline \multicolumn{3}{|l|}{ Other diseases } \\
\hline No diseases & $20.68 \pm 3.78$ & \multirow[t]{4}{*}{0.655} \\
\hline Hypertension & $20.07 \pm 3.75$ & \\
\hline Hyperlipidemia & $20.92 \pm 4.83$ & \\
\hline Metabolic syndrome (DHC) & $19.27 \pm 3.84$ & \\
\hline
\end{tabular}

${ }^{*} \mathrm{p}<0.05$. DHC: Diabetes, hyperlipidemia and cardiovascular diseases, SD: Standard deviation

with pain severity, subjects who had been diagnosed over 10 years ago having significantly higher MPQ scores $(\mathrm{p}=0.04)$. A significantly higher MPQ score was also reported among Indian patients $(\mathrm{p}=0.04)$. No significance associations were found between gender, medication, smoking status, alcohol consumption, obesity, diabetes type or other diseases, and severity of pain. 


\section{DISCUSSION}

In this study, the neuropathy symptom score was utilized to determine the PDNP. It was found that all patients' overall MPQ scores were in the range $19.15 \pm 4.14$ to $22.83 \pm 4.62$. This corresponds to the majority of patients experiencing mild to moderate pain. A study in the United Kingdom [6] reported that 80\% of patients with PDNP described their pain as either moderate or severe. It is well-established that while a certain proportion of diabetic patients with peripheral neuropathy will present with associated numbness or pain, a large number will be asymptomatic on presentation. As a result, it is essential that medical staff identify patients at risk of developing complications when and have the means of doing so [16].

The results of this study indicated that, among the ethnicities included in the study, Indian patients were more likely to experience greater neuropathy pain. This is consistent with existing research in the literature reporting Indians to be the ethnic group most affected by diabetic foot problems and other complications from diabetes. This is, in itself, corroborated to some extent by the finding of the National Health and Morbidity Survey, NHMS III [17], that the ethnic group in Malaysia exhibiting the highest rate of amputations of the lower limb was Indian. The results of this study show that the length of time for which a patient has suffered from diabetes can be a significant indicator of the severity of pain among patients having the disease for more than 10 years. This finding, that suffering from diabetes for a long time contributes to the intensity of PDNP, is consistent with a recent study in India [18], in which most patients with longstanding diabetes reported either severe or moderate pain levels.

\section{CONCLUSION}

Most patients with PDNP reported the severity of the pain to be "mild." The pain severity may be influenced by a patient's ethnicity and the length of time for which they have suffered from diabetes.

\section{ACKNOWLEDGMENT}

This study was supported by International Islamic University Malaysia (RIGS 16-286-0450).

\section{REFERENCES}

1. Kalsi A, Singh S, Taneja N, Kukal S, Mani S. Current treatment for Type 2 diabetes, their side effects and possible complementary treatments. Int J Pharm Pharm Sci 2015;7(3):13-8.

2. Tesfaye S, Boulton AJ, Dyck PJ, Freeman R, Horowitz M, Kempler P, et al. Diabetic neuropathies: Update on definitions, diagnostic criteria, estimation of severity, and treatments. Diabetes Care 2010;33(10):2285-93.
3. Tesfaye S, Selvarajah D. Advances in the epidemiology, pathogenesis and management of diabetic peripheral neuropathy. Diabetes Metab Res Rev 2012;28 Suppl 1:8-14.

4. Van Acker K, Bouhassira D, De Bacquer D, Weiss S, Matthys K, Raemen $\mathrm{H}$, et al. Prevalence and impact on quality of life of peripheral neuropathy with or without neuropathic pain in Type 1 and Type 2 diabetic patients attending hospital outpatients clinics. Diabetes Metab 2009;35(3):206-13.

5. Hussain M, Naqvi SB, Khan MA, Rizvi M, Alam S, Abbas A, et al. Direct cost of treatment of diabetes mellitus Type 2 in Pakistan. Int J Pharm Pharm Sci 2014;6(11):261-4.

6. Davies M, Brophy S, Williams R, Taylor A. The prevalence, severity, and impact of painful diabetic peripheral neuropathy in Type 2 diabetes. Diabetes Care 2006;29(7):1518-22.

7. Gore M, Brandenburg NA, Dukes E, Hoffman DL, Tai KS, Stacey B. Pain severity in diabetic peripheral neuropathy is associated with patient functioning, symptom levels of anxiety and depression, and sleep. J Pain Symptom Manage 2005;30(4):374-85.

8. Tesfaye S, Boulton AJ, Dickenson AH. Mechanisms and management of diabetic painful distal symmetrical polyneuropathy. Diabetes Care 2013;36(9):2456-65.

9. AL-Mahmood SM, Abdullah ST, Ahmad NN, Mohamed AH, Razak TA. Analgesic synergism of gabapentin and carbamazepine in rat model of diabetic neuropathic pain. Trop J Pharm Res 2016;15(6):1191-5.

10. Jacovides A, Bogoshi M, Distiller LA, Mahgoub EY, Omar MK, Tarek IA, et al. An epidemiological study to assess the prevalence of diabetic peripheral neuropathic pain among adults with diabetes attending private and institutional outpatient clinics in South Africa. J Int Med Res 2014;42(4):1018-28.

11. Spallone V, Morganti R, D'Amato C, Greco C, Cacciotti L, Marfia GA. Validation of DN4 as a screening tool for neuropathic pain in painful diabetic polyneuropathy. Diabet Med 2012;29(5):578-85.

12. Melzack R. The short-form megill pain questionnaire. Pain 1987;30(2):191-7.

13. Droz J, Howard FM. Use of the short-form mcgill pain questionnaire as a diagnostic tool in women with chronic pelvic pain. J Minim Invasive Gynecol 2011;18(2):211-7.

14. Strand LI, Ljunggren AE, Bogen B, Ask T, Johnsen TB. The short-form mcgill pain questionnaire as an outcome measure: Test-retest reliability and responsiveness to change. Eur J Pain 2008;12(7):917-25.

15. Suresh K, Chandrashekara S. Sample size estimation and power analysis for clinical research studies. J Hum Reprod Sci 2012;5(1):7-13.

16. Fatimah A, Amaramalar S, Aznida F, Norlaila M. Risk determinants of peripheral neuropathy in patients with Type II diabetes mellitus attending follow-up clinics at University Kebangsaan Malaysia Medical Center (UKMMC): A cross sectional study. Med Health 2010;5(1):34-40

17. Mimi O, Teng CL, Chia YC. The prevalence of diabetic peripheral neuropathy in an outpatient setting. Med J Malaysia 2003;58(4):533-8.

18. Bansal D, Gudala K, Muthyala H, Esam HP, Nayakallu R, Bhansali A. Prevalence and risk factors of development of peripheral diabetic neuropathy in Type 2 diabetes mellitus in a tertiary care setting. J Diabetes Investig 2014;5(6):714-21. 